\title{
Depression in late life: A hidden public health problem for Mexico?*
}

Fernando A.W agner, M.P.H., ${ }^{(1)}$ Joseph J. Gallo, M.D., M.P.H., ${ }^{(1)}$

Jorge Delva, Ph.D.'.1)

\section{Wagner FA, Gallo JJ, Delva J. Depression in late life: A hidden public health problem for Mexico? Salud Publica Mex 1999;41:189-202.}

\begin{abstract}
A bstract
Depression is one of the most important causes of disability in the world, causes considerable suffering, and problems associated with depression are extremely costly to society. Depression is one of the most common and debilitating illnesses of older people that is frequently overlooked. The most recent epidemiological study in Mexico estimated the lifetime prevalence of major depressive episodes among people 18 to 54 years old to be $7.8 \%$, only second to alcohol dependence (8.2\%). A previous study found that older adults tend to have higher levels of depression than younger adults. There are important gaps of information about depression among the elderly. Along with refined measurement approaches, further research is needed on risk and protective factors for depression as these factors might highlight the areas that need to be targeted.Addressing depression among the elderly can significantly contribute in reduced health care costs, lowered disability, morbidity and mortality. This could yield important savings, freeing resources that might become available for the attention of important health care needs.
\end{abstract}

Key words: depression; aging; primary health care; hypertension; diabetes mellitus; M exico

\author{
Wagner FA, Gallo JJ, Delva J. \\ Depresión en la edad avanzada: \\ ¿problema oculto de salud pública para México? \\ Salud Publica Mex 1999;41:189-202.
}

\section{Resumen}

La depresión es una de las causas más importantes de discapacidad en el mundo, genera considerable sufrimiento a quienes la padecen, y los problemas aso ciados con ella son extremadamente costosos para la sociedad. La depresión es una de las enfermedades más debilitantes y más comunes entre los ancianos; sin embargo, generalmente es pasada por alto. El estudio epidemiológico más reciente en México estima que la prevalencia de episodios de depresión mayor es de $7.8 \%$ en la población de entre 18 y 54 años de edad, superada únicamente por la dependencia al alcohol (8.2\%). Un estudio previo encontró que los adultos mayores tienden a presentar niveles de depresión más altos que los adultos jóvenes. Hay importantes brechas de información acerca de la depresión entre los ancianos. Es preciso afinar las técnicas de medición, y se requiere más investigación acerca de factores de riesgo y protección para la depresión, ya que ello puede dar la pauta para establecer áreas de intervención. A tender la depresión entre las perso nas de edad avanzada puede contribuir significativamente a reducir costos de atención en salud, disminuir la discapacidad, la morbilidad y la mortalidad. Esto generaría importantes ahorros y liberaría recursos que podrían ser dedicados a la atención de otras necesidades de salud.

Palabras clave: depresión; envejecimiento; atención primaria de salud; hipertensión; diabetes mellitus; México

\footnotetext{
* This work was supported by scholarship number 110421/110470 from the N ational Council on Science and Technology (CO N ACYT), Mexico, to Fernando W agner.
}

(1) Department of Mental Hygiene, School of Hygiene and Public Health, The Johns Hopkins University, Baltimore, Maryland, USA.

Fecha de recibido: 30 de junio de 1998 - Fecha de aprobado: 24 de febrero de 1999 


\section{Growth of the older population in Mexico}

$\mathrm{D}$ uring the past 50 years, the profile of the Mexican population has changed profoundly and rapidly. The population over 60 years has increased from $5.1 \%$ of the total population or one million people in 1940 to $6.1 \%$ or about five million people in 1990, and it is expected that the population aged 60 years or more will increase to $14.6 \%$ of the total population by the year $2025 .{ }^{1,2}$ In other words, since 1940 , the number of people 60 years of age and older has increased consistently, relative to the rest of the Mexican population. In all, about 17 million Mexican people will be 60 years or older in the year 2025. ${ }^{3}$

The aging of the population is associated with higher morbidity, mortality, disability, and associated costs. In part, these problems result from accumulation of toxic exposures, quality of life, and nutrition as well as traumatic events over the years, problems that interact with the naturally occurring process of general decline of the immune system among the elderly. ${ }^{4}$ The increasing number of elderly with health problems already are taxing the health care delivery system in Mexico. For example, 30\% of the beds at general hospitals are being used by older adults. ${ }^{5}$ and about $20 \%$ of all the outpatient visits are for this age group. These data show that the needs of the elderly are overpowering the available resources and capacities of the health care system in Mexico as of today. The aging of the population will undoubtedly create greater needs for appropriate health and mental health care.

In Mexico, there will be at least 17.4 million cases of mental disorders among older persons in the year 2000, $62 \%$ more cases than in $1985 .{ }^{6}$ Anxiety disorders, alcohol abuse or dependence, cognitive impairment, and affective disorders are expected to be the most prevalent problems. If studies from the United States and elsewhere are any guide, mental disorders of the elderly are often not well assessed or treated but are associated with important functional outcomes. ${ }^{7,8}$ To the extent that mental disturbances are unrecognized and not addressed, psychiatric conditions are associated with unnecessary burden and cost to older Mexicans, their families, and the nation. While we realize there are gaps in knowledge which will only be answered by careful research in Mexico, the purpose of this article is to call attention to a condition for which effective treatment is available but which frequently is under-treated in older persons, namely, depression.

\section{Depression as a public health concern}

\section{Comorbidity of depression with other public health problems}

Depression can increase the risk for somatic diseases and accidents, may accelerate or aggravate functional impairment progression, and may cause unnecessary delays in disease recovery. The body of evidence linking depression with other health problems is already impressive. Depression has been found to be associated with anxiety disorders, primarily with panic and social phobia, substance abuse, suicide, and heart attacks; also, with increased mortality in the young, in the elderly, and in depressed stroke patients. Additional problems associated with depressive illness are diminished immunological responses, diabetes mellitus, chronic pain, gastrointestinal complaints, somatoform disorders, migraine headaches, cancer, Alzheimer's disease, bone fractures, and various neurologic conditions such as Parkinson's disease and stroke. ${ }^{8,9}$

Several studies have shown that patients with depression tend to be high utilizers of medical services. ${ }^{10-12}$ In turn, the over-utilization of services is likely to have an impact on several areas of mental health care delivery, primarily due to the lack of efficiency and effectiveness that result from increases in services utilization (e.g., increased costs, diminished availability of services). For example, conservative estimates show that primary care patients who meet one or more of eight DSM-III-R criteria for major depression have higher health care costs (\$2 390) than patients with sub-threshold disorders (\$1 098), and than those who do not meet any criteria for a psychiatric disorder (\$ 749)..$^{13}$ At a 12-month follow up, it was estimated that only about $10 \%$ of the total cost in the most affected group was due to mental health care costs. Therefore, the higher costs associated with psychiatric disorders are due to greater utilization of all types of inpatient and outpatient medical services, and not just due to increased costs associated with utilization of psychiatric services. Another recent longitudinal study that focused on older adults found that health care costs for patients with significant depressive symptoms were about $50 \%$ higher than costs for those without symptoms, and the difference remained statistically significant even after controlling for differences in age, sex, and chronic medical illness. The difference in costs was not explained by increased use of specialty mental health care. ${ }^{14}$ 
Diabetes mellitus, cardiovascular disease, and depression

In response to the aging of the Mexican population, the "Programa de Reforma del Sector Salud 1995-2000" specified interventions for the adult and elderly populations with three sub-programs: tuberculosis prevention and control; hypertension detection and control; and, diabetes mellitus detection and control. ${ }^{1}$ The above response-plan is important because diabetes and hypertension have been identified as major causes of death, morbidity and disability. ${ }^{15-17}$ In addition, a study found that, on the average, diabetes and hypertension were the most expensive treatments of an institutional state care system in Mexico [\$240.42 Mexican pesos (about $\$ 30$ dollars) and $\$ 312.54$ ( $\$ 40$ dollars), respectively], as compared to prenatal care [\$92.26 (or \$ 12 dollars)] and diarrhea (\$93.76 Mexican pesos), which were the least expensive. ${ }^{18}$ Other authors have found even higher costs in hypertension medical care. ${ }^{19}$

Given that an increase of the medical problems mentioned above is associated with the aging of the population, it is important to highlight the associations found between diabetes and depression and that patients with depression are at increased risk of death from coronary heart disease (CHD) ${ }^{20}$ Recently, a longitudinal study analyzed the effects of increased depression on risk of death and stroke or myocardial infarction (MI), among a sample of 4508 individuals 60 years and older enrolled in a longitudinal clinical trial of isolated systolic hypertension in the U.S. ${ }^{21}$ The study used the Center for Epidemiological Studies of Depression (CES-D) to measure depression. A 5-unit increase in CES-D score for depressive symptoms was found to be associated with a $25 \%$ increase in the risk of death and an $18 \%$ increase in the risk of stroke or myocardial infarction, after accounting for covariates such as age, sex, race, years of education, history of MI and diabetes, and current smoking status.

Another longitudinal study estimated the risk of MI associated with a prior history of major depressive episode to be 4.54 times greater (95\% CI, 1.65 to 12.44), than among those who did not report depressive symptoms, even after controlling for coronary risk factors. ${ }^{22}$ Moreover, the study also analyzed the role of specific kinds of medicines, concluding that the association between psychotropic medication use and MI was probably a reflection of the primary relationship between depression and MI. This study addressed many of the considerations discussed by Borja-Aburto and colleagues, ${ }^{4}$ namely, the use of information from community samples, statistical power, and the use of standardized measurements and instruments for data gathering. It is becoming increasingly clear that depres- sion is a major contributor to the course and severity of heart disease, and that in later life the two conditions may have a synergistic relationship. ${ }^{23}$

\section{Suicide and depression}

The general rate of suicide in Mexico is estimated to be 2.55 per 100,000 persons ( 4.4 for males and 0.8 for females), the higher rates being found among people 75 years and older and between 15 to 19 years. ${ }^{24}$ Although the general rate of suicide in the U.S. is higher than in Mexico (11.9 suicides per 100000 persons; 19.8 for males and 4.4 for females), ${ }^{25}$ a similar ratio of male:female suicide rates is observed $(4.4 / 0.8=5.5$ in Mexico, 19.8/4.4= 4.5 in the U.S.).

Common medical conditions, treatments, medications, and depression can increase the risk of suicide. ${ }^{26}$ Although treatable, depression is often not treated, and suicide rates are high among depressed elderly persons. ${ }^{27}$ Actually, depression is the psychiatric condition most often linked to suicide among older adults. ${ }^{28} \mathrm{~A}$ consistent finding from a number of studies of older persons reveals that they had seen their physician within a short interval before completing suicide. In some cases, suicide victims thought they had terminal illness without any evidence, or thought their physician was hiding information about severe illness. In other cases, victims of suicide might have faced inadequate treatment of depression, either because they were prescribed an incorrect medication or because the dose was inadequate..$^{29}$ These findings show the importance of recognizing and adequately treating depression, particularly in primary care settings.

\section{Depression and substance use/misuse}

Using data from the National Household Survey on Addictions 1993, Tapia and colleagues explored drug use among people aged 60 to 64 years, the oldest respondents included in the survey. These authors found a high rate of psychotherapeutic drug use (28\% for women and $17 \%$ for men). The most commonly used drugs were central system depressant drugs (22\% of the women and $13 \%$ of the men). Interestingly, about $85 \%$ reported to use these drugs by medical prescription..$^{30}$ Elderly patients may receive several medications from numerous physicians in pursuit of symptomatic relief from unrecognized depression, because therapeutic interventions might be duplicated or contradictory and might be associated with the development of neuroadaptation to tranquilizers, sedatives and opiate analgesics. Transient fevers, arrhythmias and changes in mental status in the elderly may not be recognized 
as a cluster of symptoms indicating a withdrawal syndrome, and thus the cycle of dependence might be expanded. ${ }^{31}$ Thus, recognizing depression is considered an important first step in the treatment response for those who have alcohol and other drug dependence. ${ }^{32}$ Unfortunately, as noted by Gallo and Lebowitz, substance abuse and dependence have not been well studied in the elderly. ${ }^{33}$

\section{Depression and disability}

Depression not only leads to higher health care costs but also to considerable and unnecessary suffering of patients. Psychiatric disorders are associated with high levels of disability, showing a dose-response relationship (those patients with more psychiatric morbidity and co-morbidity have higher levels of disability). A World Health Organization (WHO) study of 25916 people who consecutively attended primary health care facilities in 14 countries found the functioning from depressed patients to be comparable or worse than that of patients with a major chronic medical disease. ${ }^{34}$ This finding is supported by an extensive literature review that led other researchers to conclude that minor depression was associated with absenteeism from work and was responsible for 9 to $16 \%$ of total disability days. ${ }^{35}$ As part of an international collaborative study sponsored by the World Health Organization (WHO), standardized instruments were used in a twostage sampling/screening strategy in three primary health clinics in Santiago, Chile. Disability was evaluated using two measurements: the Social Disability Scale and a self-report questionnaire. One third of primary health care patients with one or more psychological disorders suffered moderate to severe disability, a rate that was twice as high as among patients without a diagnosis of a psychological disorder. ${ }^{36}$ Unfortunately, this international study did not include older adults.

The serious implications of these findings are highlighted when viewed in relation to the findings of a study by the World Health Organization, the World Bank, and the Harvard School of Public Health on the global burden of diseases. In this cross-regional, worldwide study, the impact of several health problems was evaluated by analyzing the number of deaths attributed to a particular disease as well as the impact of premature death and disability on the population. For this purpose, the DALY (Disability-Adjusted Life Years) was developed as an indicator of disease burden. A DALY represents a lost year of healthy life. In this manner, it was found that depression (unipolar major depression) and its health and social consequences was the fourth most important cause of disease during the 1990's. This study also shows that depression will be the second most important source of disease burden by the year 2020, given the aging of the population. These findings apply to all regions of the world. ${ }^{37} \mathrm{In}$ particular, for the region comprised of Latin American and Caribbean countries, the report highlights that the group of communicable diseases will show important declines in disease burden (34.7 million DisabilityAdjusted Life Years in 1990 vs. 13.5 in 2020), while the group of non-communicable diseases will show the greatest increase. The number of DALYs associated with depression will increase more than 60\% from 1990 to the year 2020, so that disability attributed to depression will rival that due to cardiovascular disease. The next section will review studies that can help unravel the scope and distribution of depressive disorders in terms of person, time, and place.

\section{Epidemiology of depression}

\section{Mexico}

We are unable to provide recent national estimates of the prevalence and incidence of depression in Mexico. Therefore, we present findings from studies of depression in Mexico that have used probability samples based on specific populations. The rationale for limiting the revision to community and primary care health care samples is that convenient and clinical samples may confound associations of depression with referral patterns, severity and / or duration of the disorder, or functional impairment, as well as with socioeconomic factors associated with access and utilization of health services. In contrast, this review is aimed at providing an overview of the scope and impact of depression in the general population of Mexico.

Studies on depression in Mexico have focussed on different populations and have used different methodological strategies and instruments. ${ }^{38}$ This review may be useful in constructing an overview of the present and future scope of the problem. Also, we have included data from other countries to provide a general sense of the characteristics of depression in countries other than Mexico to develop a plan about what can be accomplished regarding the problem of depression from systematic, continued efforts.

An overview on some of the most important studies available in Mexico at the beginning of the 1970's led Dr. Cabildo Arellan ${ }^{39}$ to estimate the prevalence of "neurotic reactions" at about $10 \%$ to $13 \%$ of the general population, and about 1 in 4 persons over 15 years of age. Neurotic reactions were used as indicators of 
neurotic disorders, because it was thought that the diagnostic criteria for these disorders were less well defined than those for other disorders.

More recently, in 1987, a cross-sectional survey was conducted in Tijuana, Baja California, Mexico, in order to measure the scope of depressive symptoms among people 18 years of age or older..$^{40}$ Participants in that study were selected via a multi-stage, systematic random sample of 50 clusters. The data were gathered by social workers that conducted structured interviews with 991 respondents. The mean age of those participating in the survey was 34 years, and about $10 \%$ were 60 or more years old. A cutoff point of 16 or above in the CES-D questionnaire score was used as an indicator of depression. All in all, 19.1\% of males and $33.0 \%$ of females scored the same or above the caseness threshold. The sex-adjusted mean in the CES-D score was higher for those 50 years or more than the overall mean, suggesting that older adults tend to have higher levels of depression than do younger adults.

Other studies of depression in Mexicans have not focused on older persons. A study of depression among students 8-10 years old was conducted in west Guadalajara, Jalisco, (one of the three most populated Mexican cities). A multi-stage systematic random sample of 377 children was obtained (about 10\% of the 3967 registered students in third to fifth grade), gathering the data through face-to-face interviews by practicing physicians (pasantes en servicio social). The prevalence of depression was calculated using a cutoff of 16 points or above in the CES-D. Depression was the second most prevalent condition $(46.3 \%)$ with females $(52.2 \%)$ having a higher proportion than males $(40.6 \%)$. The only disorder that was more prevalent than depression was aggressive conduct disorder $(48.9 \%) .{ }^{41} \mathrm{~A}$ binational survey among adolescent students was conducted in six cities of Texas and neighboring Tamaulipas. The CES-D was also used, with a cutoff of 16 points or above. Depressive symptoms were less frequent among Mexican youths (39.4\%) than among Texan youths $(48.1 \%))^{42}$

Recently, Caraveo and colleagues used an adapted version of the World Health Organization Composite International Diagnostic Interview (CIDI), known as CIDI-Fresno, to collect data from a representative sample of adults 18-64 years old, in Mexico City. This is the most comprehensive study ever conducted in Mexico of psychiatric disorders with a large community sample. Findings from this study are being published, however, it will be possible to obtain estimates of the lifetime and 12-month prevalence of major depression and several other mental disorders, according to the 10th edition of the International Classifica- tion of Diseases (ICD-10), and the 3rd revised and 4th editions of the Diagnostic and Statistical Manual of Mental Disorders (DSM-III-R and DSM-IV). In addition, this study will yield important information regarding the association of mental disorders and disability as well as about the help seeking process among persons with mental disorders. ${ }^{43}$ Preliminary estimates of the lifetime prevalence of major depressive episode among persons 18 to 54 years old is approximately $7.8 \%$, only second to alcohol dependence $(8.2 \%){ }^{44}$

All of the studies described earlier have contributed important information regarding the scope and distribution of depression among children, adolescents and adults. However, it is necessary to acknowledge the scarcity of information on the epidemiology of depression among the elderly.

\section{Other populations}

In the United States (U.S.), the 12-month prevalence of major depression varies according to the population under study: $2-4 \%$ in community samples; $5-10 \%$ in primary care settings; $6-14 \%$ in inpatient medical wards. ${ }^{9,45}$ The prevalence of patients with depressive symptoms that fall short of meeting the criteria for a diagnosis of major depression is at least 2-3 times that of those who receive a diagnosis of major depression. Young adults are the most affected, with the elderly showing lower prevalence rates than would be expected. Estimates of the lifetime prevalence of depression based on the National Comorbidity Survey, a national representative stratified study of mental disorders in the U.S., are considerably higher for women (21.3\%) than for men $(12.7 \%) .{ }^{46}$ This high prevalence is troublesome because major depression can be recurrent and, at times, chronic. Typically, persons who suffer from depression have repeated episodes over time, but approximately 25 to $50 \%$ of cases only have a single episode. We are not aware of studies with community epidemiologic samples that have estimated the incidence or prevalence of seasonal depression, a course specifier for mood disorders included in the DSM-IV. ${ }^{47}$ However, methods of depression ascertainment in epidemiologic studies include persons who meet criteria for major depression, and are inclusive of the presence of seasonal affective disorder.

Other studies have been conducted throughout the world regarding mental disorders in general, and depression in particular, many of them based on translations of standardized instruments that include the Diagnostic Interview Schedule (DIS), the Composite International Diagnostic Interview (CIDI), the Center 
for Epidemiologic Study of Depression (CES-D) scale, and the General Health Questionnaire (GHQ). A salient finding from some studies has been that people from Latin America and Japan obtain higher scores on some sub-scales or items of these instruments when compared to the original population for which the instruments were designed. Differences may indicate that the meaning and domains of depression may be culturally sensitive. ${ }^{48-52}$ For example, Salgado-de-Snyder and Maldonado ${ }^{50}$ argue that in the U.S. a cutoff point of the CES-D score is associated with the 80th percentile, or 16 points. The corresponding cutoff threshold in a sample of adult women in rural areas of the Mexican states of Jalisco and Michoacán ought to be 18 points. At lower thresholds, the prevalence of depression would be over $60 \%$ which the authors thought was probably too high.

Another interesting methodological issue when measuring depression is that Mexican Americans are more likely than non-Hispanic Whites to endorse items related to lack of positive affect and that U.S.-born Mexican Americans are more likely to report somatic and negative affect symptoms than Mexican-born people surveyed in the U.S. ${ }^{53}$ These differences in depression between the U.S.-born Mexican Americans and those born in Mexico were not accounted for by differences in acculturation, strain, social resources, social conflict, and education. Results of additional studies on this topic suggest that unmeasured variables such as selective migration or return, or generation differences, might account for the differences in depression symptoms. ${ }^{54}$

More research is needed in this area, and an improved understanding of the cross-cultural expression of depression is necessary for a better comprehension of the problem. While we await special studies to address cultural similarities and differences of depression among the population, it may be possible to examine the influence culture has on depression by analyzing findings from studies of countries with shared cultural characteristics (i.e., Mexico and other Latin American countries, the U.S. and the United Kingdom). In this topic, studies participating in the International Consortium in Psychiatric Epidemiology are most interesting and definitely will be useful in improving our understanding of similarities and differences in the scope and distribution of psychiatric disorders across countries. The recent survey of 3012 Mexican-Americans who were born in the United States or who migrated from Mexico to Fresno County, California, U.S., is an excellent example. In this study, a probability community sample was surveyed allowing interviewees to choose the language in which they wanted to be in- terviewed (i.e., English or Spanish). Consistent with prior research among Mexican-Americans, ${ }^{55}$ this study found that Mexican immigrants have lower lifetime rates of mental disorders than decendents of Mexicans born in the U.S. In particular, an estimated 5.2\% of Mexican immigrants met criteria for at least one episode of major depression in their lifetime, while decendents of Mexicans born in the U.S had a higher rate $(14.8 \%)$. However, these rates are lower than the estimated $18.3 \%$ found by the U.S. National Comorbidity Survey for all ethnic groups of Hispanics taken together. ${ }^{44}$ Merikangas and colleagues found that despite important sociocultural differences across six countries -Mexico included-a lifetime history of mood and anxiety disorders was associated with alcohol problems or dependence, as well as with other drug problems or dependence. ${ }^{56}$

In spite of the great interest on psychological and psychiatric disorders in the primary health care sector, studies about depression are not yet common in Latin America. In addition to the studies conducted in Mexico, a few studies of psychological disorders have also been conducted in Chile. Three recent studies in Chile found similar prevalence rates of psychological disorders among patients in primary health care clinics. One of these studies used the Self-Reporting Questionnaire (SRQ) and found a prevalence of $51.9 \%$ among patients attending to two general health care clinics in Concepción. ${ }^{57}$ Another study used the Clinical Interview Schedule-Revised (CIS-R) in Lo Prado and found a prevalence rate of $53.4 \% .{ }^{58}$ In the third study, as part of an international collaborative effort coordinated by the WHO in primary health care centers, Florenzano and colleagues $^{36}$ found a weighted prevalence of $53.5 \%$ of any psychological disorder diagnosis in Santiago. The most frequent diagnosis was depression $(29.5 \%)$ followed by generalized anxiety disorder, which affected $18.7 \%$ of the patients. Unfortunately, these studies did not include substantial numbers of older adults; however, the findings highlight the high rates of distress experienced by persons receiving health care.

\section{Health services}

\section{Pathways to mental health care}

Goldberg and Huxley ${ }^{59,60}$ formulated the model of "Pathways to Mental Health Care" to describe the process by which individuals become defined as mentally ill and eventually receive mental health services. The first level includes all individuals in the community with an episode of mental disorders (which Goldberg and Huxley estimated at 260 to 315 per thousand per 
year in the United Kingdom). The corresponding filter between the first and the second level is the "illness behavior", that is, the response of the individual and the community to the symptoms (e.g., denial, neglecting, segregation, somatization, support and referral). The second level corresponds to people in primary health care who have an episode of mental disorders and seek help ( 230 per thousand per year). Thus, the filter to the next level is recognition of the mental disorder by the doctor. The third level includes those patients in primary health care who have been identified as having a mental disorder by their doctors (102 per thousand per year), and the filter to the next level consists of the referral and admission to mental health services. The fourth level corresponds to cases of mental disorders that receive specialized mental health services (24 per thousand per year). Finally, the fifth level corresponds to cases in psychiatric hospitals (6 per thousand per year).

Most persons with psychological distress never pass beyond the first two levels. Only a small proportion of people is identified and seen in specialized settings. It appears that most individuals with depressive and anxiety related disorders remain within the first two levels, while patients in the fifth level have more severe conditions that may be more disruptive, such as organic mental disorders or schizophrenia. Goldberg and Huxley provide extensive evidence that common mental disorders in the community level account for enormous suffering, severe disability and elevated financial costs. ${ }^{45}$ From the perspective of public mental health, it is essential to keep this framework in mind. Since most cases occur in the first levels of the model (that is, to up primary health care), the bulk of disability in the population will occur here, even though more severe cases will be found in the specialty sector. Improving the recognition and treatment at these first levels could have a large effect on disability due to depression on the overall population.

The World Health Organization's Study on psychological disorders in primary health care found that, on the average, about one out of every four patients who seek help in primary health care units throughout the world has an identified mental disorder. Depressive disorders are the most common of all, and about 12.8\% of all contacts have anxiety and / or depression symptoms, but insufficient in number to qualify as cases. ${ }^{61}$ Nearly one half of the patients with anxiety or depressive disorders are not identified as having the disorder by the physicians in primary care centers across the world. In addition, the study uncovered that recognizing depression by the physician does not mean that the patient will be provided with treatment, as only half were offered a drug treatment. ${ }^{61,62}$

\section{Pathways to mental health care in Mexico and in other} countries

This section describes a number of studies selected to provide a general understanding of pathways to mental health care with a focus on Mexico. We summarize these studies in Table I. One of the earliest studies of depression in Mexico was by Pérez-Toledo ${ }^{63}$ who studied depression among psychiatric patients. The study consisted in administering the Zung Depression Scale to 317 patients that sought treatment for the first time in an outpatient psychiatric clinic in Mexico City. About one out of three patients (32.8\%) was found to be depressed, and it was estimated that $31 \%$ of the cases had an intense level of depression, while $16 \%$ of the cases suffered at a more severe level.

A survey conducted among patients 65 years and older who sought general health care in a private hospital in Mexico City ${ }^{64}$ found high rates of psychological distress. In this high-risk group, the general prevalence of mental disorders in this sample was estimated to be $50.7 \%$, and the most frequent diagnoses were neurosis $(42.1 \%)$, cerebral organic syndrome without psychosis (39.4\%), and major affective disorders $(10.5 \%)$. In another study, Padilla and colleagues ${ }^{65}$ estimated the prevalence of psychiatric disorders among patients 18 to 64 years old attending the general practice service of a health center in Mexico City. The study used a systematic random sample of 501 patients, which amounted to $50 \%$ of all the patients that attended the health center during a period of 6 weeks. The study found that $51.8 \%$ of the patients presented a psychiatric disorder as measured by the GHQ-60. The most prevalent disorders were adaptation reactions $(29.1 \%)$ and neurosis (13.4\%). Of note, psychiatric care and inpatient care was necessary for $10 \%$ of the affected population or $5.3 \%$ of the entire sample in this study.

A similar study to the one mentioned above was conducted by Medina-Mora and colleagues. ${ }^{66}$ These authors conducted a survey of patients 18 to 64 years old in a general hospital service in Mexico City using the GHQ. Almost all patients attending the general practice service during a 5-week period answered the questionnaire ( $96.4 \%$ of 619$)$. In this study, the prevalence of mental disorders was estimated to be $34 \%$. Neurosis, mainly depressive neurosis, was found to be the most frequent diagnosis (25\% in females, $17 \%$ in males). Given the above findings, the authors of that study indicate that the overall prevalence proportion 


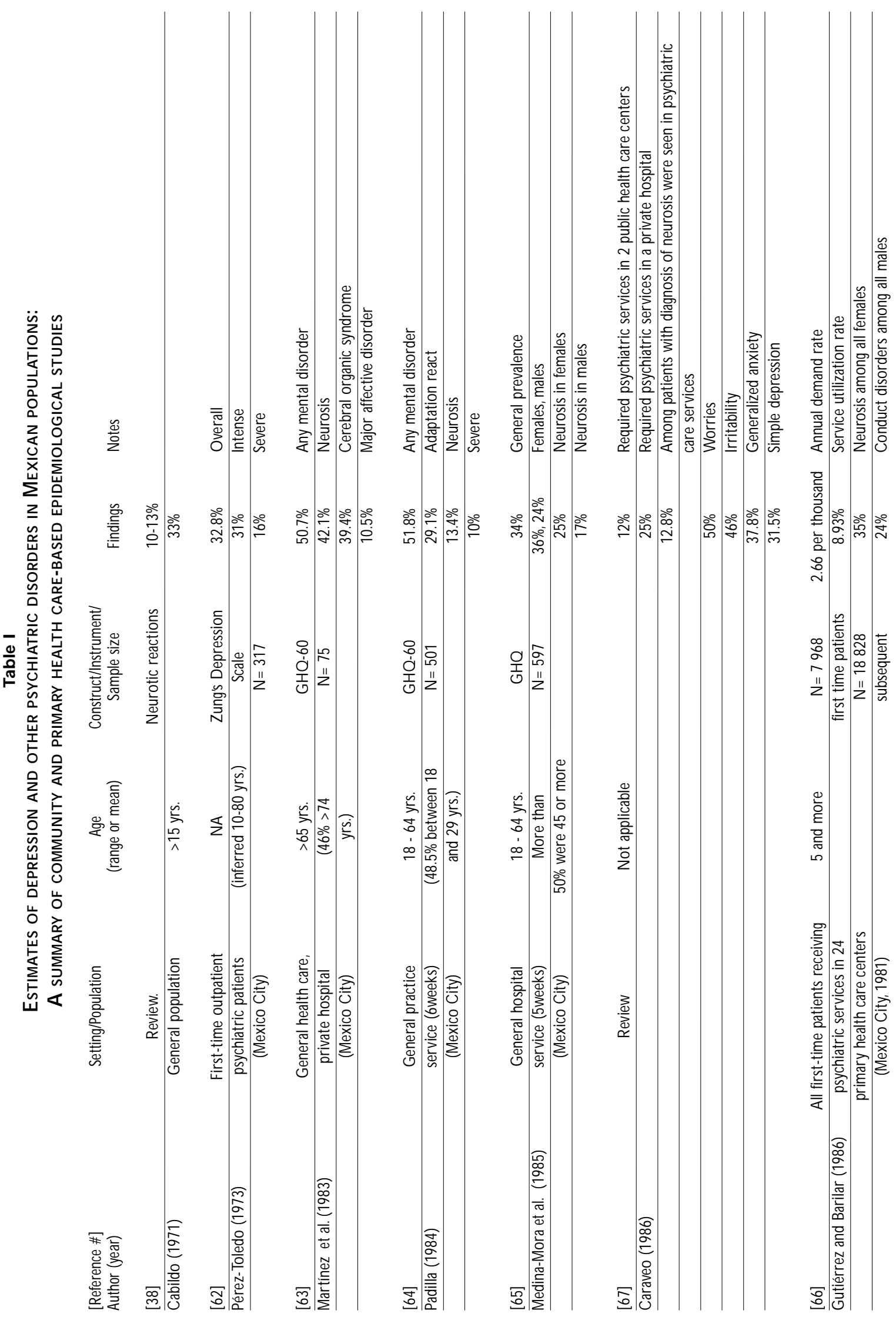



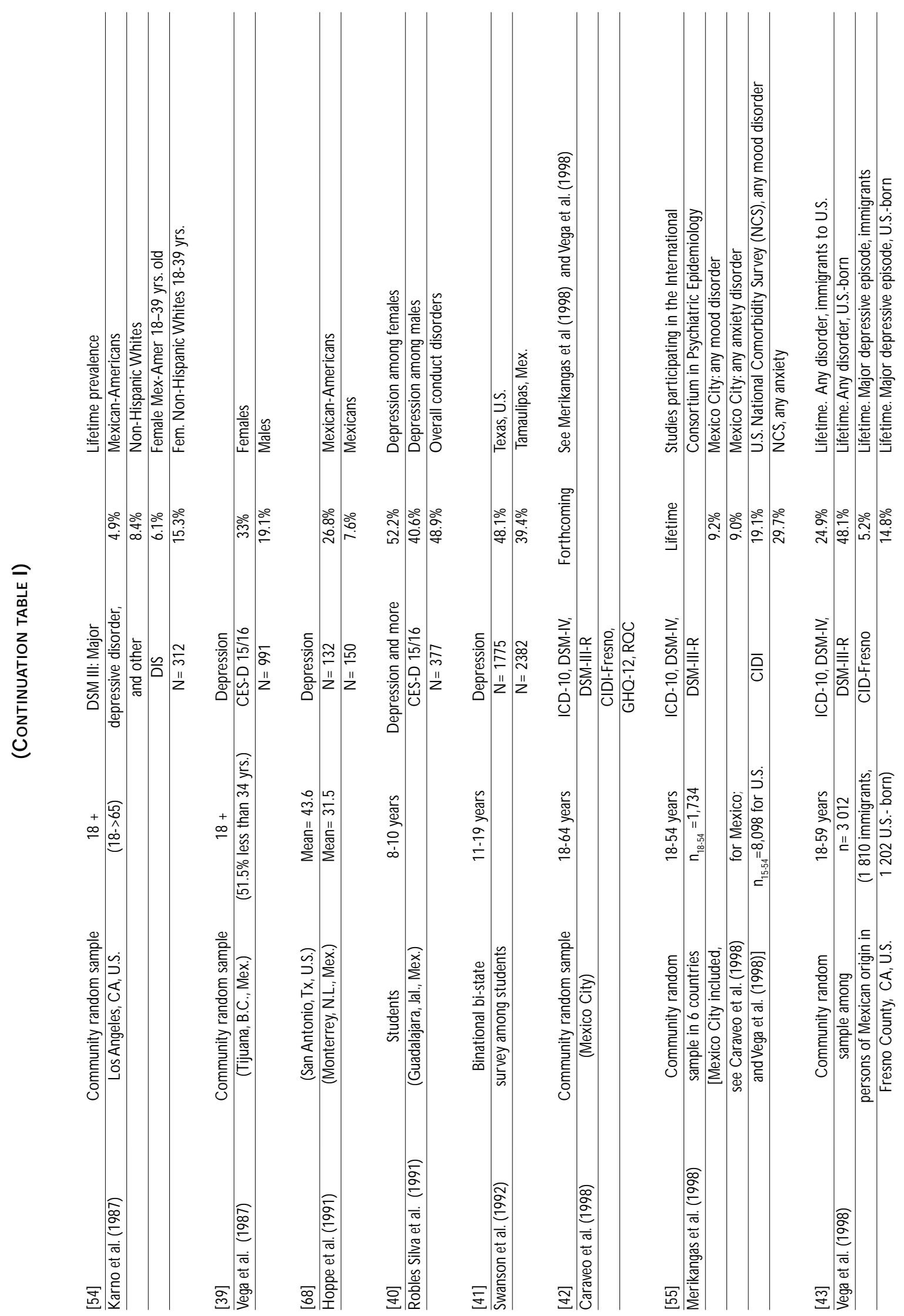
of mental disorder among this population is similar to that found in other countries, once the proper thresholds are used.

In another study of psychiatric problems in health centers, Gutiérrez-Avila and Barilar ${ }^{67}$ analyzed data on all first-time patients who received services by psychiatrists in 24 primary health centers in the Federal District of Mexico City in 1981, as well as among individuals who already had received services but continued to do so during the same year. These authors examined the proportion of potential new users that actually received services (demand rate) and the proportion of individuals with a disorder that received services, regardless of their status as new or continuing services user (the service utilization rate). Patients were diagnosed by the treating psychiatrist according to the Eighth Edition of the International Classification of Diseases. The annual demand rate was found to be 2.66 per 1000 inhabitants, while the service utilization rate during 1981 was 8.93 per 100 patients. The most frequent problems identified in this study included neurosis (35\% of all female patients) and conduct disorders ( $24 \%$ of all male patients). In this study, several factors seemed to indicate that primary health care is not the main pathway to the health care system. In light of the rather small demand and utilization rates, Gutiérrez and Barilar hypothesized that either the demand of mental health services among adults is very low or that the population may get specialized services directly from the third level of (mental) health care or in the private sector.

Caraveo and colleagues ${ }^{68}$ concluded that the percentage of patients requiring psychiatric care was 12\% in two public primary care centers and $25 \%$ in a private general hospital. These authors were also able to estimate that only $12.8 \%$ of patients with a diagnosis of neurosis in primary health care were actually seen in psychiatric care services. The most prevalent psychiatric syndromes in a sample of patients from a general family practice were worries $(50 \%)$, irritability $(46 \%)$, generalized anxiety (37.8\%) and simple depression $(31.5 \%)$. In the same study, Caraveo and colleagues report factors associated with recognition of mental disorders in primary care settings. They conclude that recognition of mental disorders varied as a function of the patient's symptomatology, chronicity of disorders, and implicitly, the time available to the doctor to know the patient.

A binational survey among Mexican-Americans and Mexican family practice patients in San Antonio, Texas, U.S., and in Monterrey, Nuevo León, Mexico, found that rates of depression and anxiety were not significantly different in the two samples. However, rates of disorders in Monterrey were substantially lower than those reported in previous studies. For example, the age-adjusted rate of depression for U.S.-born Mexican Americans was over three times the rate for those born in Mexico (26.8\% vs. 7.6\%, respectively). Findings from this study need to be replicated, important regional and cultural differences are possibly present within regions and populations in Mexico, but it is also possible that the samples were not representative, despite the random procedures that were used in both cities. ${ }^{69}$

In 1988, The World Health Organization conducted a study of 1554 patients newly referred to mental health services, to examine the pathways to psychiatric care in 11 countries. These countries, included Cuba, Czechoslovakia, India, Indonesia, Kenya, Mexico, Portugal, Pakistan, People's Democratic Republic of Yemen, Spain, and the United Kingdom. In this study, somatic problems were found to be the most common initial presenting problem, and the majority of the patients had previously received some form of treatment for their present problem. ${ }^{62}$ The proportion of patients with depressive disorders across centers was comparable. Contrary to what is often reported, somatic complaints were not more frequent in developing countries. Additionally, the three main service providers on the pathways to psychiatric services were: (a) the primary care physician, (b) the general hospital doctor, and (c) the native or religious healers. At least one of them is involved with about $80 \%$ of all patients in all centers. The pathway pattern seen in Mexico was similar to that found in European centers but with more direct referrals from the community to specialty mental health services. Mexican patients presented the highest median delay from the time they first developed symptoms to the time they received specialized mental health care.

Results from the Mexican sites of the WHO study show that the median delay from the onset of the disorder to obtaining psychiatric services varies considerably according to the disorder and type of institution. Specifically, affective disorders had a median delay of 21.5 to 30 weeks from onset of the disorder to the time when the patient reached the psychiatric service. Neurosis, stress and somatoform disorders had a corresponding median delay between 48 and 52 weeks. However, it is important to mention that other disorders had much larger median delays, such as physiologic dysfunctions associated to mental disorders (494 weeks) and personality and conduct disorders, with 208 weeks of median delay. The study in these two 
psychiatric services found that the chief complaints leading $60 \%$ of the patients to seek health care were affective and conduct disorders. Finally, the authors of this study highlight the small proportion of patients who received services because less than $30 \%$ of these patients received drug treatment. ${ }^{70}$

\section{Problems for depression identification and diagnosis}

Recognition of depression among the elderly may be difficult both in epidemiological surveys and in the context of health care units. First, it is interesting to note that surveys have found lower prevalence rates of depression among the elderly than in younger populations. This may be explained by consideration of several factors that may act alone or in combination. Among these factors, co-morbidity with somatic problems may directly or indirectly explain a good proportion of the underestimation of depression: directly, because within the hierarchic categories of psychiatric diseases (e.g., the DSM and the ICD), depression could not be diagnosed in the presence of any other disease that could account for one or more depression symptoms, and indirectly, because older people are more likely to attribute their problems to somatic rather than to emotional origins. ${ }^{71,72}$ Persons 65 years or older are less likely to report feelings of sadness / anhedonia than younger persons. ${ }^{73,74}$

Problems that people may face in recognizing depression include such characteristics as lack of knowledge or understanding of symptoms by both patients and caregivers, the tendency to avoid psychiatric care, fears of expenses for medical consultations and medicines, a cultural misconception of aging as a naturally depressing process, social isolation, and lack of social networks that could help recognize symptoms. Also, physicians may fail to detect depression in patients with cognitive impairment, or when caregivers (family, staff) are unable or not willing to inform of current symptoms because of the issues that were described earlier. $7,73,75$

The implications of the failure to treat depression are multiple, including iatrogenic injury, patient complaints due to aggressive medical testing, and comorbid disease progression. ${ }^{76}$ Failure to identify or diagnose depression has important implications both for estimating the scope of the problem as well as for timely treatment. Problems and implications for detecting depression may be particularly complex among the elderly.

\section{Depression, primary health care, and health care reform}

In order to meet the increasing and more complex needs of the population, the Mexican Health System has undergone a process of reorganization that is expected to allow for more effective, timely, and satisfactory delivery of health care services. If the current conditions of the elderly prevail in oncoming years, the health care system will have to deal with a population that has very low school attainment level, low income, and little or no savings. ${ }^{38}$ However, as important as they are, access and socioeconomic barriers will not be the only challenges the health care system will have to address. It will also be necessary to develop a health care system that integrates primary health care and the mental health care of older persons. Fragmentation of services might prove particularly problematic for a population that presents an additional need for establishing and maintaining rapport and orientation to ensure treatment compliance and continuity. The creation of bridges that foster mutual understanding between specialties, with advocacy for integration of mental health into a general medical framework, is an additional challenge the health system reform may need to consider. ${ }^{33}$

\section{Where do we go from here?}

The aging of the population is no longer a phenomenon solely observed in developed nations (e.g., Japan, United States, Germany). Indeed, the age group comprised by individuals 65 year and older has been the fastest growing age group in Mexico. An anticipated consequence of the aging of the population is the increase in psychological disorders that must be addressed by the Mexican health care system. Our review of the literature on depression indicates the need for further studies given that depression and related health problems produce considerable suffering to the individuals, and are extremely costly.

Several steps can be considered in order to best respond to the health care needs of the aging population. First, it is important to document the extent of depression among the elderly in Mexico. However, given that prior studies have shown a cultural bias in measurement, especially with the use of screening and diagnostic instruments developed for English speaking populations, studies must be conducted to establish the validity and reliability of the instruments with the populations under investigation. While it is clear 
that refined measurement approaches need to be developed, we also need to further advance our knowledge on the risk and protective factors for depression as these factors might highlight the areas that need to be targeted. Although a number of risk and protective factors for depression among the elderly have been identified in several countries, this type of work needs to progress quickly in Mexico. An equally important area of investigation is the study of help-seeking behaviors among the Mexican elderly. According to Goldberg and Huxley's pathways-to-care model it would seem as though the majority of cases of depression will not be identified, perhaps, until other medical and/or more serious problems have occurred. Therefore, the study of help-seeking behaviors among the Mexican elderly must not be neglected. Simultaneously, the study in primary health care clinics about recognition of patients with depression by attending physicians could help increase the proportion of cases that receive early interventions, and therefore prevent further complications and co-morbidity.

The reduction of depression among the elderly can bring important benefits not only for the individual in terms of decreased suffering but also for health care providers in the form of reduced health care costs. A growing literature indicates that addressing depression among the elderly can significantly contribute in reduced costs, lowered disability, morbidity and mortality. This could yield important savings, freeing resources that might become available for the attention of other equally important health care needs. As stated in the quote from the Mexican Health Care Reform in the introduction section of this paper, the seeds of future problems are being planted today. A multifaceted, multidisciplinary approach to readying the health and mental health care services for the increasing numbers of older Mexicans is essential in order to meet the already existing challenges, and will be even more important during the coming years.

\section{Acknowledgments}

Dr. Gallo is a Brookdale National Fellow in Geriatrics and Dr. Delva is a National Institute on Drug Abuse (NIDA) postdoctoral fellow (United States) at the time the paper was prepared. We gratefully acknowledge Dr. Héctor E. Velasco for his helpful comments and suggestions to this manuscript.

\section{References}

1. Secretaría de Salud. Programa de Reforma del Sector Salud, 1995-2000. México D.F.: Secretaría de Salud, 1996. Electronic file.
2. Ham-C hande R. El envejecimiento: Una nueva dimensión de la salud en México. Salud Publica Mex 1996;38:409-418.

3. Gómez de León J. Envejece la población mundial: retos para México. O bservador Internacional 1993;1:34-5. Q uoted by: Ruiz-Arregui L, Rivera-Márquez JA.C aracterísticas de la morbilidad en población mexicana de avanzada edad: Un análisis de la Encuesta N acional de Salud 1988. Salud Publica Mex 1996;38:430-437.

4. Borja-A burto VH, Bustamante-Montes P, Rascón-Pacheco RA.Aumenta la depresión clínica el riesgo de muerte por causas no violentas? Salud Publica Mex 1994;36:51-60.

5. D urán-Arenas L, Sánchez R,Vallejo M,C arreón J,Franco F. Financiamiento de la atención a la salud de la población de la tercera edad. Salud Publica Mex 1996;38:501-512.

6. Levav I, Lima BR, Somoza-Lennon M, Kramer M, González R. Salud Mental para todos en América Latina y el $C$ aribe. Bases epidemiológicas para la acción. Bol 0 ficina Sanit Panam 1989;107:196-220.

7. G allo JJ, Rabins PV, Lyketsos CG, T ien AY,Anthony JC. D epression without sadness: Functional outcomes of nondysphoric depression in later life. J Am Geriatr Soc 1997;45:570-578.

8. Gallo JJ, Rabins PV, lliffe S.The 'Research Magnificent' in late life: Psychiatric epidemiology and the primary health care of older adults. Int J Psychiatry 1997;27:185-204.

9. Burvill PW. Recent progress in the epidemiology of major depression. Epidemiol Rev 1995;17:21-31.

10. Martínez-Lanz P, Medina-Mora ME, Campillo C. Evaluación del costo de utilización de servicios en la práctica médica general. Salud Mental 1984:7:63-67.

11. Katon W.The epidemiology of depression in primary care. Int J Psychiatry 1987;17:93-112.

12.W ells KB, Stewart A, Hays RD, Burnam MA, RogersW, D aniels MB et al. The functioning and well-being of depressed patients: Results from the Medical O utcomes Study. JAMA 1989;262:914-919.

13. Simon G, 0 rmel J,VonKorff M, Barlow W. Health care costs associated with depressive and anxiety disorders in primary care. Am J Psychiatry 1995;152:352-357.

14. Unützer J, Patrick DL, Simon G, G rembowski D,W alker E, Rutter $C$ et al. Depressive symptoms and the cost of health services in $\mathrm{HMO}$ patients aged 65 years and older. JAMA 1997;277:1618-1623.

15. Borges-Yáñez AS, Gómez-D antés H, Gutiérrez-Robledo LM, FabiánSan Miguel G, Rodríguez R. Utilización de servicios hospitalarios por la población anciana de la Ciudad de México. Salud Publica Mex 1996;38: 475-486.

16. Castro V, Gómez-D antés H, N egrete-Sánchez J,Tapia-C onyer R. Las enfermedades crónicas en las personas de 60-69 años. Salud Publica Mex 1996;38:438-447.

17. Ruiz-Arregui L, Rivera-Márquez JA .C aracterísticas de la morbilidad en población mexicana de avanzada edad: Un análisis de la Encuesta $N$ acional de Salud 1988. Salud Publica Mex 1996;38:430-437.

18.Villarreal-Ríos E, Montalvo-A Imaguer G, Salinas-MartínezAM, G uzmánPadilla JE,Tovar-C astillo N H, G arza-Elizondo ME. C osto en el primer nivel de atención. Salud Publica Mex 1996;38:332-340.

19. Bobadilla JL, Frenk J, Cowley P. Zurita B, Q uerol J, Villarreal E et al. Economía y salud: documentos para el análisis y la convergencia. El universal de servicios de salud. México: Fundación Mexicana para la Salud, 1994. 20. Milani RV, Lavie CJ. Behavioral differences and effects of cardiac rehabilitation in diabetic patients following cardiac events.Am J Med 1996;100: 517-523.

21. W assertheil-Smoller S, Applegate W B, Berge K, Chang CJ, D avis BR, $G$ rimm $R$ Jr. et al. Change in depression as a precursor of cardiovascular events. Arch Intern Med 1996;156:553-561.

22. Pratt LA, Ford DE, Crum RM, Armenian HK, Gallo JJ, Eaton W W. Depression, psychotropic medication, and risk of myocardial infarction. Prospective data from the Baltimore ECA follow-up. Circulation 1996;94: 3123-3129. 
23. Glassman AH, Shapiro PA. Depression and the course of coronary artery disease. Am J Psychiatry 1998;155:4-11.

24. Borges G, Rosovsky H, C aballero MA, Gómez CC. Evolución reciente del suicidio en México: 1970-1991. Anales del Instituto Mexicano de Psiquiatría 1994;5:15-21.

25. Anderson RN, Kochanek MA, Murphy SL. Report of final mortality statistics, 1995. Monthly Vital Statistics Report 1997;45 suppl 2:1-80.

26. Valente SM. Evaluating suicide risk in the medically ill patient. N urse Practitioner 1993;18:41-50.

27. W asylenki D. Depression in the elderly. Can Med Assoc 」1980;122: 525-532.

28. C onwellY, D uberstein PR, C ox C, Herrmann JH, Forbes N T, C aine ED. Relationships of age and $A$ xis I diagnoses in victims of completed suicide: A psychological autopsy study. Am J Psychiatry 1996;153:1001-1008. 29. Caine ED, Lyness JM, C omwellY. D iagnosis of late-life depression: Preliminary studies in primary care settings. American Journal of Geriatric Psychiatry 1996;4 suppl 1:S45-50.

30.Tapia-C onyer R, Cravioto P, Borges-Yáñez A, D e la Rosa B. Consumo de drogas médicas en la población de 60 a 65 años en México. Encuesta $N$ acional de Adicciones 1993. Salud Publica Mex 1996;38:458-465.

31. Miller F,W hitcup S, Scaks M, Lynch PE. Unrecognized drug dependence and withdrawal in the elderly. DrugAlcohol Depend 1985;15:177-179.

32. Miller N S, Klamen D, Hoffman N G, Flaherty JA. Prevalence of depression and alcohol and other drug dependence in addictions treatment populations. Psychoactive D rugs 1996;28:111-124.

33. Gallo JJ, Lebowitz BD.The epidemiology of common mental disorder in late life:Themes for the new century. Psychiatric Services. In press. 34.0 rmel J,VonKorff M, U tsunTB, Pini S, Korten A, O Idehinkel T.C ommon mental disorders and disability across cultures: Results from the W HO Collaborative Study on Psychological Problems in General Health Care. JAMA 1994;272:1741-1748.

35. Beck DA, Koenig HG. Minor depression: A review of the literature. International Journal of Psychiatry in Medicine 1996;26:177-209.

36. Florenzano R,A cuña J, Fullerton C, C astro C. Results from the Santiago de Chile Centre. In: Ü stün TB, Sartorius N, ed. Mental illness in general health care: An international study. N ew York: John W iley \& Sons, 1995: 247-284.

37. Murray CJL, Lopez AD, eds. The global burden of disease. Summary. C ambridge: $H$ arvard University Press, 1996

38. De la Fuente R, Medina-Mora ME, C araveo J. Salud mental en México. Mexico,D.F.:Instituto Mexicano de Psiquiatría/Fondo de Cultura Económica, 1998.

39. Cabildo-Arellano HM. Panorama epidemiológico de los desórdenes psiquiátricos en la República Mexicana. Salud Publica Mex 1971;13:53-63. 40.VegaW A, Kolody B, Hough RL, Figueroa G. Depressive symptomatology in Northern Mexico adults. Am J Public Health 1987;77:1215-1218.

41. Robles-Silva L, Mercado-Martínez FJ. Prevalencia de entidades mentales en escolares de un área metropolitana de Guadalajara. Salud Publica Mex 1991:33:49-55.

42. Swanson JW, LinskeyA O Q Q uintero-Salinas R. PumariegaAJ, H olzer CE. A binational school survey of depressive symptoms, drug use, and suicidal ideation. I Am A cad Child A dolesc Psychiatry 1992:31:669-678.

43. Caraveo J, Martínez N , Rivera B. Un modelo para los estudios epidemiológicos sobre la salud mental y la morbilidad psiquiátrica. Salud Mental 1998:21(1):48-57.

44.VegaW A, Kolody B,A guilar-G axiola S,A Iderete E, C atalano R, C araveoAnduaga J. Lifetime prevalence of DSM-III-R psychiatric disorders among urban and rural Mexican Americans in California. Arch Gen Psychiatry 1998:55(9):771-778.

45. Goldberg D. Epidemiology of mental disorders in primary care settings. Epidemiol Rev 1995;17:182-190.
46. Kessler RC, McG onagle KA, Zhao S, N elson CB, Hughes M, Eshleman $S$ et al. Lifetime and 12-month prevalence of DSM-III-R psychiatric disorders in the United States: Results from the $\mathrm{N}$ ational Comorbidity Survey. Arch Gen Psychiatry 1994;51:8-19.

47.A merican Psychiatric Association. Diagnostic and statistical manual of mental disorders. 4th edition. W ashington D.C.: A merican Psychciatric Association, 1993

48. Lewis G, Araya RI. Is the General Health Q uestionnaire (12 items) a culturally biased measure of psychiatric disorder? Soc Psychiatry Psychiatr Epidemiol 1995;30:20-25.

49. Iwata N, Uno B, SuzukiT. Psychometric properties of the 30-item $G$ eneral Health Q uestionnaire in Japanese. Jpn J Psychiatry N eurol 1994;48: 547-556.

50. Salgado-de Snyder VN , Maldonado M.C aracterísticas psicométricas de la Escala de D epresión del C entro de Estudios Epidemiológicos en mujeres mexicanas adultas de áreas rurales. Salud Publica Mex 1994;36:200-209. 51. Mariño MC, Medina-Mora ME, C haparro JJ, González-Forteza C. C onfiabilidad y estructura factorial del CES-D en una muestra de adolescentes mexicanos. Revista Mexicana de Psicología 1993;10:141-145.

52. Roberts RE, Chen YW. Depressive symptoms and suicidal ideation among Mexican-origin and Anlgo adolescents. I Am Acad Child Adolesc Psychiatry 1995;34(1):81-90.

53. Golding JM,A neshensel CS, Hough RL. Responses to depression scale items among Mexican-A mericans and non-H ispanic whites. J C lin Psychol 1991;47:61-75.

54. Golding JM, Burnam AM. Immigration, stress, and depressive symptoms in a Mexican-American Community. Journal of N erv Ment Dis 1990;178:161-171.

55. Karno M, Hough RL, Burnam A, Escobar JI,T imbers D M, Santana F et al. Lifetime prevalence of specific psychiatric disorders among Mexican A mericans and non-Hispanic W hites in Los Angeles. Arch Gen Psychiatry 1987:44:695-701.

56. Merikangas K. Comorbidity of substance use disorders with mood and anxiety disorders: Results of the International Consortium in Psychiatric Epidemiology.Addict Behav 1998:23(6):893-907.

57. U ribe M, Vicente B, Saldivia S, Retamales I, Rioseco P, Boggiano GG. Prevalencia de trastornos mentales en el $N$ ivel Primario de Atención en la Comuna de Talcahuano. Rev. Psiquiatría 1992;9: 1029-1033.

58. Lewis G, Pelosi AJ,Araya R, D unn G. Measuring psychiatric disorder in the community: A standardized assessment for use by lay interviewers. Psychol Med 1992:22:465-486.

59. Goldberg D, Huxley P. Mental illness in the community:The pathway to psychiatric care. London:Tavistock Publications, 1980.

60. Goldberg D, Huxley P.Common Mental D isorders.A Bio-Social Model. London:Tavistock/Routledge, 1992.

61. Sartorius N, Ü stün TB, Lecrubier Y,W ittchen HU. Depression comorbid with anxiety: Results from the W HO Study on Psychological Disorders in Primary Health Care. Br J Psychiatry 1996;168 suppl 30:38-43. 62. Gater R, Almeida e Sousa D, Barrientos G, Caraveo J, Chandrashekar $C R$, D hadphale $M$ et al.The pathways to psychiatric care:A cross-cultural study. Psychological Medicine 1991;21:761-774.

63. Pérez-Toledo MA. La depresión en una población urbana de la Ciudad de México.Arch Invest Med 1974;5:51-58.

64. Martínez-Lanz P, Medina-Mora ME, Padilla P, Caraveo J, Campillo SC. Prevalencia de trastornos emocionales en personas de edad avanzada. Salud Publica Mex 1983;25:612-619.

65. Padilla P, Mas C, Ezbán M, Medina-Mora ME, Peláez O. Frecuencia de trastornos mentales en pacientes que asisten a la consulta general de un centro de salud. Salud Mental 1984;7:72-78.

66. Medina-Mora ME, Padilla G P, Mas CC, Ezban BM, C araveo J, Campillo $\mathrm{SC}$ et al. Prevalencia de trastornos mentales y factores de riesgo en una 
población de práctica médica general.Acta Psiquiatr Psicol Am Lat 1985; 31: 53-61.

67. Gutiérrez-Avila JH, Barilar-Romero E. Morbilidad psiquiátrica en el primer nivel de atención de la Ciudad de México. Bol 0 ficina Sanit Panam 1986;101:648-658.

68. Caraveo AJ, Gonzalez FC, Ramos LL, BP. N ecesidades y demandas de atención en los servicios de salud mental. Salud Publica Mex 1986;28: 504-514.

69. Hoppe SK, Garza-Galindo T, Leal-Isla C, Leon RL. Mental disorders among family practice patients in the United States-Mexico border region. Soc Psychiatry Psychiatr Epidemiol 1991;26:178-182.

70. C araveo-Anduaga MC, Mas-C ondes C. N ecesidades de la población y desarrollo de servicios de salud mental. Salud Publica Mex 1990;32: 523-531.
71. Knauper B,W ittchen HU. Diagnosing major depression in the elderly: Evidence for response bias in standardized diagnostic interviews? Journal of Psychiatr Res 1994;28:147-164.

72. Heithoff $K$. Does the ECA underestimate the prevalence of late-life depression? J Am Geriatri Soc 1995:43:2-6.

73. G allo JJ. Epidemiology of mental disorders in middle and late life: $C$ onceptual issues. Epidemiol Rev 1995:17:83-94.

74. Henderson AS. D oes aging protect against depression? Soc Psychiatry Psychiatr Epidemiol 1994;29:107-109.

75. Ramsay R, Fahy T. Recent Advances. Psychiatry. Br Med J 1995;311: 167-170.

76. Katon W, Shulberg H. Epidemiology of depression in primary care. Gen Hosp Psychiatry 1992;14:237-247. 